\title{
MORPHO-FUNCTIONAL CHANGES IN TEMPOROMANDIBULAR JOINT IN CASE OF DENTAL DEFECTS COMPLICATED BY LOWER JAW DISTAL SHIFT
}

\section{Valeriy Konnov ${ }^{1 凶}$, Natalia Bulkina², Anush Arushanyan', Ekaterina Pichugina ${ }^{1}$, Tatyana Matitsyna ${ }^{1}$, Marina Vorobieva ${ }^{1}$, Rustam Mukhamedov', Angelica Khodorich ${ }^{7}$}

\author{
${ }^{1}$ Department of Orthopedic Dentistry; Saratov State Medical University, \\ Saratov \\ 2 Department of Therapeutic Dentistry; Saratov State Medical University, \\ Saratov
}

$\triangle$ konnovvaleriy@rambler.ru

ABSTRACT - In order to identify morphological and functional changes in the temporomandibular joint, 40 patients with disturbed dentition complicated by a mandibular distal shift were examined. This pathology has been found to contribute to morphological and functional changes in the temporomandibular joint, whereas comprehensive treatment requires an individual approach.

KEYW ORDS - temporomandibular joint, occlusion

\section{NTRODUCTION}

The prevalence of defects in the dentition among the adult population reaches $80.0-85.0 \%$, and in the elderly aged beyond 60 , the index reaches $100.0 \%$. Loss of the chewing group of teeth is often accompanied by a distal displacement in the mandible, which leads to structural and functional changes in the temporomandibular joint $[1-5]$.

Despite the wide variety of clinical and experimental studies involving the temporomandibular joint, the issue of its morphological and functional status for various pathologies has not been studied to the full yet [6-14].

Aim of study

to identify anatomical, topographic and functional changes in the temporomandibular joint through the treatment of patients with disturbed dentition complicated by the lower jaw distal shift.

\section{MATERIALS AND METHODS}

Functional status assessment and X-ray examination of the temporomandibular joint were performed in 40 patients featuring defects in the dentition complicated by a distal shift of the lower jaw. The comparison group included 10 patients with orthognathic bite.

To evaluate the anatomical and topographic status of the temporomandibular joint, we used lateral tomography performed on a universal radiological unit ORTHOPHOS 3 (SIEMENS).

To evaluate the functional status of the temporomandibular joint, a list of clinical dysfunction symptoms was used with the symptoms further assessed in points (Helkimo).

The results obtained through the study were processed by statistical analysis methods. For smaller sampling, nonparametric research methods were used.

\section{RESULTS AND DISCUSSION}

Analysis of lateral temporomandibular joint tomograms revealed an asymmetric arrangement of the articular heads in the articular fossa in $60 \%$ of cases. In $60 \%$ of the cases, at wider mouth opening, the articular head was located behind the articular tubercle apex; in $40 \%$ - under its apex. The width of the articular head on the left was $10.77 \pm 0.74 \mathrm{~mm}$; on the right $10.66 \pm 0.57 \mathrm{~mm}$. The articular head immersion depth in the articular fossa was $5.00 \pm 0.67 \mathrm{~mm}$ on the left and $4.77 \pm 0.49 \mathrm{~mm}$ on the right. The depth of the articular fossa was $2.38 \pm 0.36$ times that of the previous indicator on the left, and $2.46 \pm 0.41$ times on the right side.

The articular tubercle height on the left was $9.90 \pm 0.34 \mathrm{~mm}$ and $10.82 \pm 0.84 \mathrm{~mm}$ on the right. The articular tubercle inclination angle to the line drawn from the lower edge of the ear canal to the top of the articular tubercle was $59.80 \pm 2.97^{\circ}$ on the left and $60.00 \pm 2.65^{\circ}$ on the right.

The anterior articular gap on the left was $3.74 \pm 0.22 \mathrm{~mm}$ and on the right $-3.89 \pm 0.29 \mathrm{~mm}$; the posterior articular gap on the left was $4.71 \pm 0.90$ $\mathrm{mm}$ and on the right $-4.27 \pm 0.53 \mathrm{~mm}$. The distance from the articular fossa bottom to the top of the articular head was $5.25+0.85 \mathrm{~mm}$ on the left and $5.80 \pm 0.52 \mathrm{~mm}$ - on the right.

The calculations aimed at identifying the dysfunction index in patients of this group revealed that the temporomandibular joint function was impaired in $88.2 \%$ of the cases. Mild dysfunction was observed 
in $35.3 \%$ of the cases; $29.4 \%$ of the patients were found to suffer from a moderate degree of the dysfunction, with another $23.5 \%$ of the cases featuring a severe degree.

The patient treatment plan was designed individually and in all the cases included two stages. Stage 1 implied correcting the position of the lower jaw and recovery of the interalveolar distance, while Stage 2 involved rational prosthetics.

The treatment contributed to a change in the articular head topography. So, the front position of the articular head increased by $45 \%$, which came along with a decrease in its central and rear positions frequency. The articular heads location symmetry increased by $40 \%$. In $25 \%$ of the cases, the position of the articular head was observed at the top of the articular tubercle, which did not allow the treatment to be considered complete, which, in turn, required additional measures to eliminate this position of the articular heads.

The treatment contributed to a change in the anterior and posterior portions of the joint space. The anterior articular gap decreased on the left by $0.71 \mathrm{~mm}$ $(\mathrm{p}<0.05)$. The posterior articular gap increased on the left by $2.74 \mathrm{~mm}$ and on the right - by $2.13 \mathrm{~mm}$ $(\mathrm{p}<0.05)$.

Due to the treatment, the functional status of the temporomandibular joint changed, evidence to that being an increase of $17.6 \%$ in the number of observations revealing no signs of temporomandibular joint dysfunction. There was also a decrease observed in the incidence of moderate and severe dysfunction by $11.7 \%$ and $23.5 \%$, respectively.

The study of the temporomandibular joint status in patients with disturbed dentition complicated by the lower jaw distal shift based on X-ray examination, revealed that its elements underwent morphological and anatomical, as well as topographic changes, which manifested themselves through a decrease in the articular tubercle height by $2 \mathrm{~mm}$ on the left with $\mathrm{p}<0.005$ and $1.08 \mathrm{~mm}$ on the right at $\mathrm{p}<0.01$. A decrease in the articular tubercle height led to a reduced articular fossa depth by a similar value of the indicator pointing at these changes.

The joint space width in the anterior section was $1.44 \mathrm{~mm}$ wider on the left at $\mathrm{p}<0.005$ and $1.39 \mathrm{~mm}$ wide on the right at $\mathrm{p}<0.01$; in the upper section, the increase in the index was $2.15 \mathrm{~mm}$ on the left at $\mathrm{p}<0.05$ and $2.80 \mathrm{~mm}$ on the right at $\mathrm{p}<0.005$. A change in the articular head topography was also confirmed by a decrease in the articular fossa immersion depth by 2.70 $\mathrm{mm}$ on the left and $3.03 \mathrm{~mm}$ on the right at $\mathrm{p}<0.005$.

The treatment of the patients went along with a decrease in the incidence of clinical signs of severe and moderate dysfunction by $23.5 \%$ and $11.7 \%$, respectively, which resulted in an increase in mild dysfunction and the absence of any dysfunction signs by $17.6 \%$, respectively.

\section{CONCLUSION}

The outcomes of our study allow concluding that impaired dentition, complicated by the lower jaw distal shift, contribute to morphological and functional changes in the temporomandibular joint. The developing pathology is rather rigid, which requires a comprehensive approach to treatment.

\section{REFERENCES}

1. Korobkeev A.A., Domenyuk D.A., ShKarin V.V., DMitrienKo S.V., Weisheim L.D., KonNOV V.V. Anatomical features of the interdependence of the basic parameters of the dental arches of the upper and lower jaws of man. Medical news of North Caucasus. 2018. - Vol. 13. - № 1-1. - P. 66-69. (In Russ., English abstract). DOI - https://doi.org/10.14300/ mnnc.2018.13019.

2. KorobKeEv, A.A. Changes in the structural elements of the temporomandibular joint with distal occlusion / A.A. Korobkeev, D.A. Domenyuk, E.G. Vedeshina, V.V. Konnov, O.Yu. Lezhnina, Ya.A. Korobkeeva // Medical news of North Caucasus. 2017. - Vol. 12. - № 1. - P. 72-76. (In Russ., English abstract). DOI - https://doi.org/10.14300/ mnnc.2017.12020.

3. Morphofunctional changes in temporomandibular joint correlating with its morphological variations in patients with dentition defects complicated by distal occlusion / V.V. Konnov, A.P. Vedyaeva, D.Kh. Razakov, E.N. Pichugina, T.V. Matytsina, S.N. Salnikova, M.V. Vorobeva, R.N. Mukhamedov, IV. Matysina // Archiv EuroMedica. - 2019. - Vol. 9, № 1. - P. 52-58. https://doi.org/10.35630/2199-885X/2019/9/1/52

4. Functional status of masticatory muscles at occlusion disturbances accompanied with displaced mandible / S.V. Konnov, D.Kh. Razakov, V.V. Konnov, A.R. Arushanyan, R.N. Mukhamedov, A.S. Khodorich, V.A. Mikailova // Archiv EuroMedica. - 2018. - T. 8, № 1. - P. 41-42.

5. Clinical image of temporomandibular joint dysfunction in patients with dentition defects complicated with displaced mandible / S.V. Konnov, E.N. Pichugina, V.V. Konnov, A.A. Bizyaev, S.N. Salnikova, A.R. Arushanyan, V.A. Mikailova // Archiv EuroMedica. - 2018. - T. 8, № 1. - P. 42-43.

6. Temporomandibular joint morphology at orthognatic bite / A.R. Arushanyan, V.V. Konnov, A.P. Vedyaeva, D.Kh. Razakov, T.V. Matytsina, D.N. Maslennikov, R.N. Mukhamedov, A.S. Khodorich, IV. Matysina // Archiv EuroMedica. - 2019. - Vol. 9, № 1. - P. 18-19. https://doi.org/10.35630/2199-885X/2019/9/1/18

7. Radiological specifics of temporomandibular joint structure in case of dentition issues complicated with 
distal occlusion / S.V. Konnov, A.A. Bizyaev, V.V. Konnov, E.V. Pichugina, S.N. Salnikova, A.S. Khodorich, V.A. Mikailova // Archiv EuroMedica. - 2018. - T. 8 , № 1. - P. 39-40.

8. Specifics of occlusion disturbances in adults with distal occlusion due to dentition defects / S.V. Konnov, A.R. Arushanyan, V.V. Konnov, D.Kh. Razakov, R.N. Mukhamedov, E.N. Pichugina, V.A. Mikailova // Archiv EuroMedica. - 2018. T. 8, № 1. - P. 40-41

9. Causes behind distal occlusion / M.V. Vorobieva, V.V. Konnov, N.V. Bulkina, A.A. Bizyaev, D.N. Maslennikov, A.S. Khodorich, E.S. Popko, S.V. Konnov, I.V. Matytsina // Archiv EuroMedica. - 2019. - Vol. 9, № 1. - P. 191-193. https://doi.org/10.35630/2199$885 \mathrm{X} / 2019 / 9 / 1 / 191$

10. Clinical manifestations of temporomandibular joint dysfunction in patients with free-end edentulous space / E.N. Pichugina, V.V. Konnov, N.V. Bulkina, T.V. Matytsina, M.V. Vorobeva, S.N. Salnikov, R.N. Mukhamedov, V.A. Mikailova, I.V. Matysina // Archiv EuroMedica. - 2019. - Vol. 9, № 1. - P. 175-176. https://doi.org/10.35630/2199-885X/2019/9/1/175

11. Dmitrienko T.D., Domenyuk D.A., Porfyriadis M.P., Arutyunova A.G., KondratyuK A.A., Subbotin R.S. Connection between clinical and radiological torque of medial incisors at physiological occlusion. Archiv Euro Medica, 2019; Vol. 9; 1: 29-37. https://doi.org/10.35630/2199$885 \mathrm{X} / 2019 / 9 / 1 / 29$

12. Dmitrienko S.V., Fomin I.V., Domenyuk D.A., Kondratyuk A.A., Subbotin R.S. Enhancement of research method for spatial location of temporomandibular elements and maxillary and mandibular medial incisors. Archiv Euro Medica, 2019; Vol. 9; 1: 38-44. https://doi.org/10.35630/2199$885 \mathrm{X} / 2019 / 9 / 1 / 38$

13. Davydov B.N., Konnov V.V., Domenyuk D.A., Ivanyuta S.O., Samedov F.V., Arutyunova A.G. Morphometric characteristics and correlation relationships of bone structures of TMJ-jaw joint in extending concepts of individually typological variability // Medical alphabet. Series "Dentistry". - 2019 . - Vol. 3. - 23 (398). - P. 44-50. DOI: 10.33667/2078-56312019-3-23(398)-44-50

14. Konnov V.V., Domenyuk D.A., IVAnyuta I. V., IVANYUTA S. O. Optimization of treatment tactics of patients with distal occlusion of dentition according to results of functional, clinical and X-ray studies of temporomandibular joint // Medical alphabet. Series "Dentistry". - 2019 . - Vol. 3 - - 23 (398). - P. 58-63. DOI: $10.33667 / 2078-5631-2019-3-23(398)-58-63$ 